\title{
Analysis of soil moisture condition under different land uses in the arid region of Horqin sandy land, northern China
}

\author{
C. Y. Niu ${ }^{1,2}$, A. Musa ${ }^{1}$, and Y. Liu ${ }^{1,2}$ \\ ${ }^{1}$ Institute of Applied Ecology, Chinese Academy of Sciences, Shenyang 110016, China \\ ${ }^{2}$ College of Resources and Environment, University of Chinese Academy of Sciences, Beijing 100049, China \\ Correspondence to: A. Musa (alamusa@iae.ac.cn)
}

Received: 5 June 2015 - Published in Solid Earth Discuss.: 21 July 2015

Revised: 15 September 2015 - Accepted: 9 October 2015 - Published: 23 October 2015

\begin{abstract}
Land use plays an important role in controlling spatial and temporal variations of soil moisture by influencing infiltration rates, runoff and evapotranspiration, which is important to crop growth and vegetation restoration in semiarid environments, such as Horqin sandy land in north China. However, few studies have been conducted comparing differences of dynamics of soil water conditions and the responses of soil to infiltration under different land use types in semiarid area. Five different land use types were selected to analyze soil moisture variations in relation to land use patterns during the growing season of 2 years. Results showed that soil moisture condition was affected by different land uses in semi-arid sandy soils. The higher soil moisture content among different land uses was exhibited by the grassland, followed by cropland, poplar land, inter-dunes and shrub land. The temporal variations of soil moisture in different land uses were not always consistent with the rainfall due to the dry sequence. Moreover, soil water at the surface, in the root zone and at the deep soil layer indicated statistical differences for different types of land cover. Meanwhile, temporal variations of soil moisture profile changed with precipitation. However, in the deep soil layer, there was a clear lag in response to precipitation. In addition, seasonal variations of profile soil moisture were classified into two types: increasing and waving types. And the stable soil water layer was at $80-120 \mathrm{~cm}$. Furthermore, the infiltration depth exhibited a positive correlation with precipitation under all land uses. This study provided an insight into the implications for land and agricultural water management in this area.
\end{abstract}

\section{Introduction}

Soil is an important source of goods service and resources that essential to humankind. Soils have the ability to clean water sources, thus improving human health (Helmke and Losco, 2013; Keesstra et al., 2012). Most importantly, the soil system is the key component of the Earth system that controls the water, mineral and organic matter cycles and there is a need to research different aspects of the soil and land degradation that affect the fate of the Earth system (Ganjegunte et al., 2014; Mukhopadhyay and Maite, 2014; Brevik et al., 2015).

Soil water content is essential in controlling the soil processes involving the physical, chemical, and biological processes of the soil system (Brevik et al., 2015). In general, these processes that take place in soil strongly depend on the quantity and composition of water. In the case of the water infiltration process, soil water content dictates that water flows across the soil surface, reaches the soil profile, or, finally, percolates to recharge aquifers, which is essential to understand the hydrological cycle (Cerdà, 1999).

It is known that the irrational land uses may impact on soil water, resulting in decreased and uneven infiltration (Markus et al., 1994), poor germination and reduced yields (Abadi Ghadim, 2000), accelerated leaching of agrochemicals (Taumer et al., 2006), increased runoff and enhanced erosion (Doerr et al., 2000). Li et al. (2009) showed that land use change from woodland to grassland decreased soil water by $18 \%$ during 1981-2000 in an agricultural catchment of the Loess Plateau. Cerdà (2000) reported that soil erodibility was greater under agricultural land use compared with scrubland under arid environments, indicating that cultivating the 
land under certain conditions might contribute to increasing soil erosion and runoff. Therefore, understanding soil water variations under different land use types is critical for agricultural water management and land erosion control (Gao et al., 2014; Starr, 2005; Ziadat and Taimeh, 2013).

Soil water exhibits a tremendous heterogeneity in space and time (Gomez-Plaza et al., 2000). Therefore, spatial and temporal variations of soil moisture have always been the critical issues in vegetation restoration and water resource management, especially in the semi-arid and arid ecosystems (Brevik et al., 2015; Yu et al., 2015). Additionally, land use change contributes to the variability of soil moisture, resulting in soil deterioration, agricultural productivity decline and land degradation (Biro et al., 2013; Fu et al., 2003; Leh et al., 2013; Parras-Alcántara and Lozano-García, 2014).

Moreover, land use can affect precipitation infiltration, which is of great importance to vegetation restoration and crop production in arid areas (Wang et al., 2008; Ziadat and Taimeh, 2013). Infiltration is the movement of water into the soil from the surface by downward or gravitational flow (Thompson et al., 2010; Zhang et al., 2010). It is the feedback between the infiltration of water from precipitation and the water use characteristics of the particular vegetation community that ecologically predominates in an area that determines the moisture state of the soil in the root zone (Sandvig and Phillips, 2006). Some studies have shown that plant biomass and productivity increased significantly with increasing soil infiltration rates, which have close relationships with covered vegetation types (Benegas et al., 2014; Finley and Glenn, 2010; Fu et al., 2015; Zhang et al., 2014; Zheng et al., 2015). In addition to types and coverage degrees of vegetation (Cerdà, 1998; Molina et al., 2007), precipitation patterns (Wang et al., 2008), antecedent soil water content (Guo et al., 2014) and soil properties (Neris et al., 2012) also play the influential role in the water infiltration process.

Researches have focused on the dynamics of soil water conditions and the responses of soil water to precipitation infiltration under the land-surface processes in semi-arid region (Huang et al., 2012). However, previous studies have investigated that spatial and temporal variation of soil water under a certain land use type, and drawing significant research attention is lacking on the differences of dynamics of soil water conditions under different land use types. Thus, it is necessary to understand the comparisons of the dynamics of soil water conditions under different land use types. This not only lays the foundation for the effective use of water resources, but also plays an important role in the land productivity evaluation and desertification recovery in arid land.

The overall aim of this paper was to describe how sandy soil moisture responds to different vegetation types among different land uses types in Horqin sandy land. The specific objectives of this study were the following: (1) to examine patterns and dynamics of soil moisture under different vegetation types; (2) to analyze differences in vertical soil mois- ture distribution as well as the influence of precipitation on profile soil water for different land uses.

\section{Materials and methods}

\subsection{Study area}

This study was conducted at the Ulan'aodu Station in the west of the Horqin sandy land $\left(43^{\circ} 02^{\prime} \mathrm{N}, 119^{\circ} 39^{\prime} \mathrm{E}\right)$, northeast of China. Ulan'aodu Station, built in 1975 and affiliated with the Institute of Applied Ecology of the Chinese Academy of Sciences, is one of the monitoring network stations of the Department of Desertification Control, State Forestry Administration of China. Horqin sandy land is located in the semi-arid environmental region of northern China. Due to the long-term influences of human activities (e.g., extensive firewood consumption, heavy grazing and land reclamation for agriculture) and climate changes (e.g., changes of precipitation regimes and temperature), this region has suffered serious desertification over recent decades, resulting in the scattered tree grassland to be the Horqin sandy grassland (Zuo et al., 2009). To date, most sandy grasslands have degenerated into fixed, semi-fixed, semi-mobile and mobile sandy lands (Liu et al., 2009; Zuo et al., 2009). The elevation of this region is about $480 \mathrm{~m}$, and the climate is temperate, semiarid continental and monsoonal, and it is characterized by low precipitation and frequent occurrence of strong winds. The mean annual precipitation is $284.4 \mathrm{~mm}$, of which $70 \%$ occurs from June to August. The mean annual open-pan evaporation ranges from 2000 to $2500 \mathrm{~mm}$. The average aridity index is 1.99 , the relative humidity varies between $50 \sim 55 \%$, and drought is serious in the spring (Alamusa et al., 2014). The mean annual temperature is $6.2^{\circ} \mathrm{C}$, annual frost-free period is $140 \mathrm{~d}$ and the mean annual wind velocity is $4.2 \mathrm{~m} \mathrm{~s}^{-1}$. The landscape is characterized by gently undulating, mobile, semi-mobile, and fixed sand dunes with inter-dune bottomlands (Alamusa et al., 2014). Soil properties are characterized by their coarse texture and loose structure with high proportion of sand (85-95\%) and low organic matter content (0.15-0.5\% organic C) (Su et al., 2004). The soils are vulnerable to wind erosion, particularly after cultivation. The most widely distributed sandy vegetation type was Mongolian flora including grasses (e.g., Pennisetum centrasiaticum L., Cleistogenes squarrosa L., Phragmites australis L.), shrubs (e.g., Caragana microphylla kom, Salix gordejevii, Hedysarum fruticosum pall.), and subshrubs (e.g., Artemisia halodendron L., Artermisia frigida L.).

\subsection{Experimental design}

Five typical land use types were selected to be research plots in Horqin sandy land, including poplar land (poplar), grassland (fenced grassland), cropland (maize), inter-dunes and shrub land (Caragana korshinskii kom), respectively (Fig. 1). 


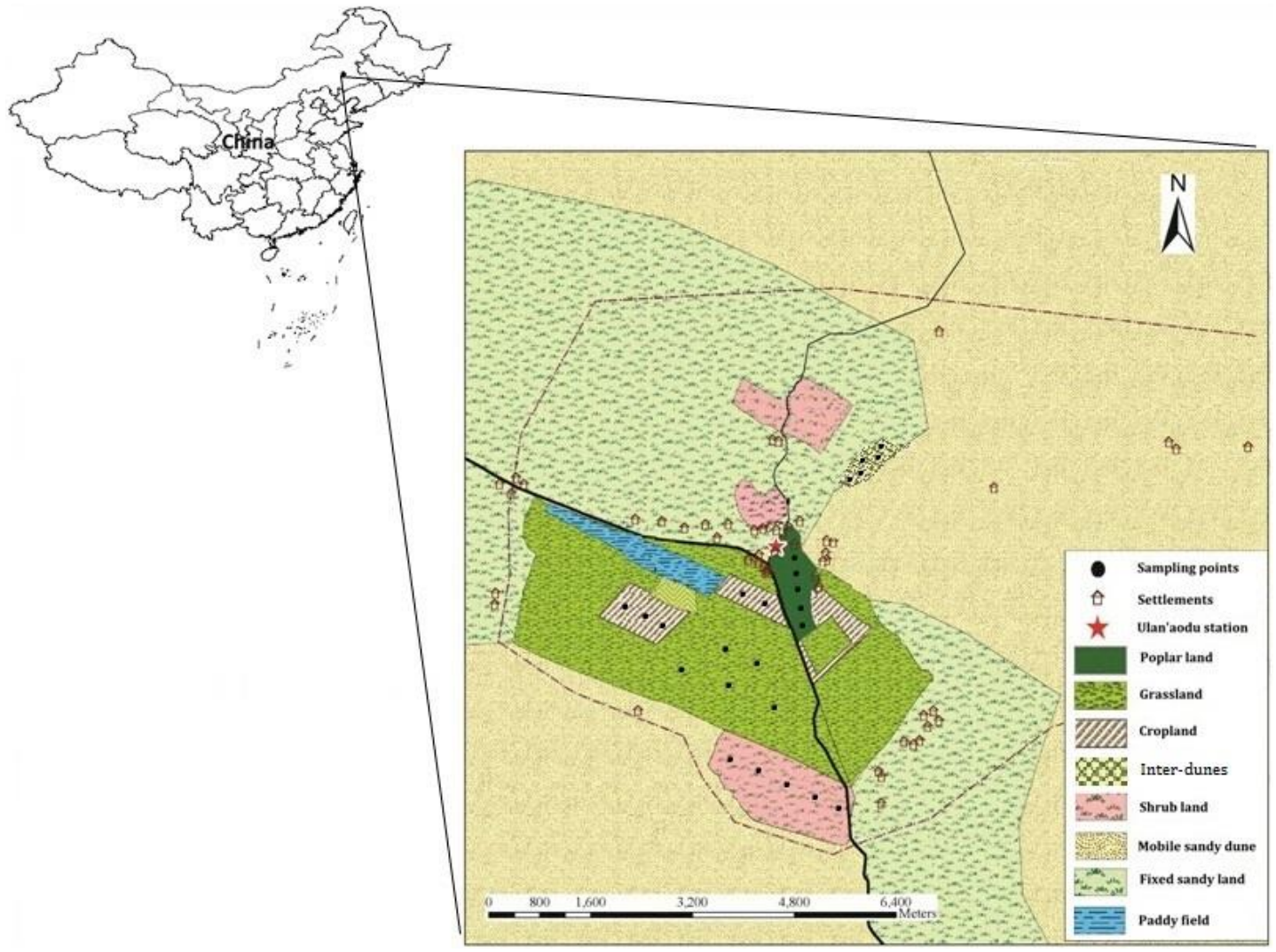

Figure 1. Land use types and soil water sampling points in the experiment area.

16 years ago, there was $400 \mathrm{~m} \times 600 \mathrm{~m}$ of poplar land in the flat sandy land. The plant density was $1.5 \mathrm{~m} \times 2.0 \mathrm{~m}$, and the average height and diameter was 22.6 and $16.3 \mathrm{~cm}$, respectively. Herbaceous plants and litter were observed on the ground.

Grassland was present in the flat sandy land with an overall area of about $2.4 \times 10^{7} \mathrm{~m}^{2}$ without shrubs and arbor. The community was mainly composed of perennial grass, including Calamagrostis epigejos and Spodiopogon sibiricus Trin with an average height of $52.6 \mathrm{~cm}$.

Cropland was present in the flat sandy land with an area of about $5.0 \times 10^{4} \mathrm{~m}^{2}$. Cropland was reclaimed from grassland over the past decades. The annual maize was the main crop in this rainfed cropland.

Inter-dune research plots were selected between fixed sandy dunes and mobile sandy dunes with $400 \mathrm{~m} \times 500 \mathrm{~m}$ area. The vegetation species consisted of Agriophyllum squarrosum, Calamagrostis epigejos, Salix flavida, Potentilla chinensis, Caragana korshinskii kom and so on.

Shrub land was mainly located in the dunes based on mobile dunes, which were one or three consecutive dunes area between 1.6-2.4 $\times 10^{6} \mathrm{~m}^{2}$. Caragana korshinskii kom community land was selected as the shrub land with a slop of $30^{\circ}$, which was planted by $1.0 \mathrm{~m} \times 1.5 \mathrm{~m} 23$ years ago, and the average height and crown was 1.8 and $2.2 \mathrm{~m}$, respectively.
Measured vegetation cover and soil properties were shown in Table 1 for different land uses.

Precipitation and potential evaporation were measured at the meteorological station in Ulan'aodu.

\subsection{Field methods}

The $20 \mathrm{~m} \times 20 \mathrm{~m}$ research plots were set in the center of five types of land uses, and five sample plots $(4 \mathrm{~m} \times 4 \mathrm{~m})$ were set randomly in each type of five land uses. Soil moisture measurements were taken at a depth of $0-120 \mathrm{~cm}$ at each plot, and profiles were divided into $0-20,20-40,40-60,60-80,80$ 100 and $100-120 \mathrm{~cm}$ at $20 \mathrm{~cm}$ intervals. Soil samples were taken out by a drill, and soil moisture was measured gravimetrically (the soil samples were oven-dried at $105^{\circ} \mathrm{C}$ for 12-14 $\mathrm{h}$ based on oven drying method). At each plot, three points were randomly chosen to calculate the average value of soil moisture. The measuring time was from 15 April to 15 October in 2002 and 2003 with a 15 day interval.

The groundwater table was observed using groundwater observation well in each area of land uses. In addition, plant roots were generally distributed at soil layers of $0-80 \mathrm{~cm}$. Therefore, soil layers of 0-20, 0-80 and 80-120 cm were defined as surface horizon, root zone and deep soil layer, respectively. In this study, surface soil water was the value of 
Table 1. Vegetation and soil characteristics at $0-20 \mathrm{~cm}$ for the five land uses in study area.

\begin{tabular}{|c|c|c|c|c|c|}
\hline \multirow[t]{2}{*}{ Land use } & \multirow{2}{*}{$\begin{array}{l}\text { Land cover type } \\
\text { (plant species) }\end{array}$} & \multirow{2}{*}{$\begin{array}{r}\text { Canopy cover } \\
\text { percent }(\%)\end{array}$} & \multirow{2}{*}{$\begin{array}{l}\text { Buck density } \\
\qquad\left(\mathrm{g} \mathrm{cm}^{-3}\right)\end{array}$} & \multicolumn{2}{|c|}{ Soil texture } \\
\hline & & & & $\begin{array}{l}\text { Sand percent } \\
(>0.01 \mathrm{~mm})\end{array}$ & $\begin{array}{r}\text { Clay percent } \\
(<0.002 \mathrm{~mm})\end{array}$ \\
\hline Poplar land & Populus davidiana & 78 & 1.32 & 87.3 & 12.7 \\
\hline Grassland & $\begin{array}{l}\text { Calamagrostis epigejos and Spodi- } \\
\text { opogon sibiricus Trin }\end{array}$ & 90 & 1.23 & 80.85 & 19.15 \\
\hline Cropland & Zea mays & 86 & 1.19 & 93.05 & 6.95 \\
\hline Inter-dunes & $\begin{array}{l}\text { Agriophyllum squarrosum, Calam- } \\
\text { agrostis epigejos, Salix flavida, and } \\
\text { Potentilla chinensis }\end{array}$ & 80 & 1.55 & 84.7 & 15.3 \\
\hline Shrub land & Caragana korshinskii kom & 65 & 1.46 & 94.5 & 5.5 \\
\hline
\end{tabular}

$0-20 \mathrm{~cm}$ soil water; root zone soil water was the mean value of 0-20, 20-40, 40-60 and 60-80 cm soil water; and deep layer soil water was the mean value of $80-100$ and 100$120 \mathrm{~cm}$ soil water (Gao et al., 2014).

To indicate the infiltration depth of rainfall and its effects on vertical soil moisture changes, we measured soil water at the day (1-2 days) before rainfall events, after rainfall events (1-2 days), and before the next rainfall events, respectively. Considering the hysteresis of rainfall infiltration process, soil water was measured with an interval of days after rainfall events. The lengths of time intervals were dependent on the precipitation; in general, the larger the amount of precipitation, the longer the time interval. Four types of rainfall were selected to evaluate vertical soil water changes derived from precipitation events in 2002 (Gao et al., 2014).

First, the low rainfall was taken from $2.6 \mathrm{~mm}$ precipitation event on 24 April 2002. To show profile soil water variations for five land uses, soil water was observed at $0-120 \mathrm{~cm}$ on 23, 25 April 2002.

Second, the medium rainfall was taken from $16.2 \mathrm{~mm}$ precipitation events on 9 and 10 June 2002. To indicate profile soil water variations for five land uses, soil water was measured at $0-120 \mathrm{~cm}$ on 8,11 June 2002 .

Third, the high rainfall was taken from $40.5 \mathrm{~mm}$ precipitation events on 11-13 July 2002. To explore profile soil water variations for five land uses, soil water was surveyed at 0 $120 \mathrm{~cm}$ on 11,15 July 2002.

Fourth, the extreme-high precipitation was taken from $102.4 \mathrm{~mm}$ precipitation events on 4, 5 and 6 August 2002. To explore profile soil water variations for five land uses, soil water was observed at $0-120 \mathrm{~cm}$ on 3 and 15 August 2002.

In order to determine the effect of precipitation on soil water changes, the absolute differences were calculated between soil water content at $0-120 \mathrm{~cm}$ intervals after precipitation and that before precipitation for each land use. We hypothesized that the absolute difference was defined as a significant change resulting from precipitation infiltration if it was positive and more than $0.5 \%$, or else, was defined as a stochastic change (Gao et al., 2014).

\subsection{Data analysis}

Statistical analyses were performed to test the influence of land use on soil moisture using a one-way ANOVA (Analysis of Variance), and comparisons of the difference between mean water content in different land uses were implemented using the least significant difference (LSD) method (at the $p<0.05$ level). The analyses were conducted through SPSS Statistics v17.0@ 2008 SPSS Inc.

\section{Results}

\subsection{Rainfall and evapotranspiration}

Precipitation of June, July and August was higher than the other months in 2002 and 2003, and evapotranspiration was always higher than precipitation for each month. Moreover, according to the meteorological data recorded for each month, the annual precipitation from June to August was over $70 \%$ of the whole year. The annual potential evapotranspiration is about $1500 \mathrm{~mm}$ in growing season (from April to October ), about 5 times larger than the precipitation (300 mm) (Fig. 2).

\subsection{Comparisons of vertical soil water in different land uses}

Significant differences of soil water were observed among three layers in five land uses (Table 2). First, the soil water content of grassland was significantly $(p<0.05)$ higher than that of the other land uses in comparison of surface soil water, while, in cropland and poplar land, surface soil water was markedly higher than that of inter-dunes and shrub land. However, there were no significant differences on surface soil water between inter-dunes and shrub land. Second, soil moisture of grassland was also remarkably higher than the other land uses in root zone, while the shrub land was evidently lower than that in the other land uses. Furthermore, the soil water of grassland and inter-dunes was conspicuously higher than the other land uses in the deep soil layer, while shrub 


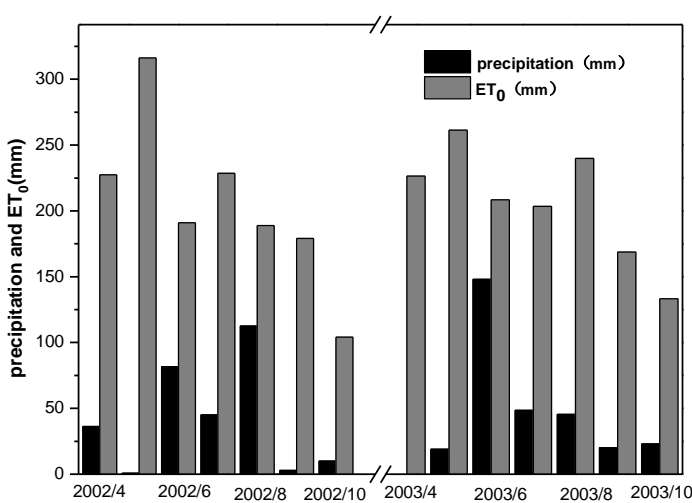

Figure 2. Monthly precipitation and potential evapotranspiration $\left(\mathrm{ET}_{0}\right)$ during the study period.

Table 2. Mean water content at different layers of five land uses. $P$ value refers to the probability of same soil water values of analysis of variance in the $95 \%$ percent significance level. Values in each column with the same letter are not significantly $(p<0.05$, LSD) different among land uses.

\begin{tabular}{llll}
\hline \multicolumn{4}{c}{ Soil water content $(\%)$} \\
\hline Land use & $\begin{array}{l}\text { Surface } \\
(0-20 \mathrm{~cm})\end{array}$ & $\begin{array}{l}\text { Root zone } \\
(0-80 \mathrm{~cm})\end{array}$ & $\begin{array}{l}\text { Deep layer } \\
(80-120 \mathrm{~cm})\end{array}$ \\
\hline Poplar land & $3.77 \mathrm{~b}$ & $5.97 \mathrm{~b}$ & $12.1 \mathrm{~b}$ \\
Grassland & $11.54 \mathrm{a}$ & $12.55 \mathrm{a}$ & $21.65 \mathrm{a}$ \\
Cropland & $3.72 \mathrm{~b}$ & $6.68 \mathrm{~b}$ & $9.06 \mathrm{bc}$ \\
Inter-dunes & $1.66 \mathrm{c}$ & $4.32 \mathrm{c}$ & $14.37 \mathrm{ab}$ \\
Shrub land & $1.93 \mathrm{c}$ & $1.95 \mathrm{~d}$ & $1.86 \mathrm{c}$ \\
$P$ value & $<0.001$ & $<0.001$ & 0.00781 \\
\hline
\end{tabular}

land was significantly lower than the other land use patterns in deep soil layer, too.

\subsection{Temporal variations of soil water in different land uses}

First, the poplar land soil moisture content was increasing after rainfall and was consistent with the temporal variations of rainfall (Fig. 3). Second, grassland soil water variations showed two and three peaks in 2002 and 2003, respectively, and the peaks appeared in May, August and May, and in July and September, respectively; this was not synchronous with the rainfall temporal variations. Third, cropland showed a peak in May and September, respectively, which was not concurrent with rainfall in 2002, when the only peak appeared in August due to the lack of relevant data in 2003, which was accordant with rainfall. Fourth, the inter-dune soil water variations showed two peaks at the beginning of June and August, which was consistent with rainfall changes; inter-dune soil moisture showed a decreasing trend in 2003. Moreover, shrub land soil water variations showed single peak both in 2002 and 2003, and appeared in July and June with a value

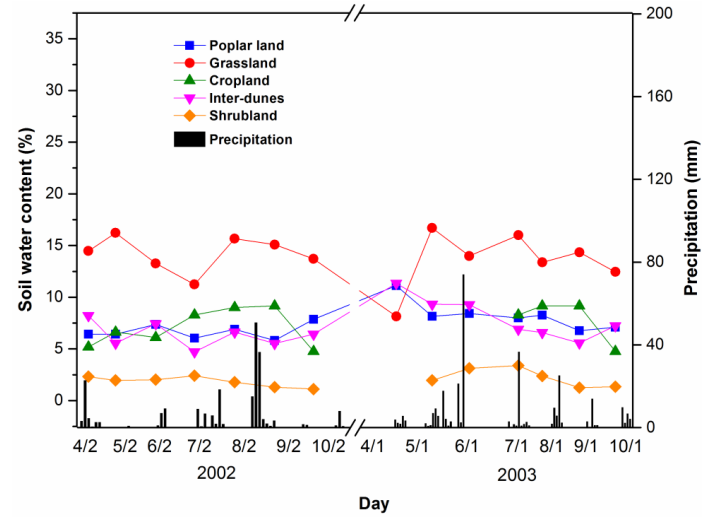

Figure 3. The temporal variations of mean soil moisture within 0 $120 \mathrm{~cm}$ in five land uses.

of 2.42 and $2.38 \%$, respectively, which was consistent with rainfall.

Variations of soil water profiles changed with time and were dependent on rainfall (Fig. 4a-c). Under different land uses, surface soil water varied with the changes of precipitation patterns (Fig. 4a). Surface soil water of each land use pattern presented higher soil moisture content during the peak of precipitation between July and August. For instance, soil surface water of grassland reached a peak value $(14.78 \%)$ in August 2002 when a heavy rainfall event $(112.6 \mathrm{~mm})$ occurred. However, soil water presented a complicated variation in root zone (Fig. 4b). For example, soil water of five land use patterns presented an increasing trend in August 2002 due to the heavier rainfall. On the contrary, soil water presented a decreasing trend from June to September when heavier rainfall still continued during this period. There were not obviously changes in deep soil layers under different land uses with the changes of precipitation (Fig. 4c), and deep soil water presented a smooth temporal change during the whole growing season.

Furthermore, in spring (Fig. 5a), soil water in different land uses, except cropland, exhibited a low-high-low trend from 0 to $120 \mathrm{~cm}$, and the peak values appeared at $60 \mathrm{~cm}$ (grassland), $110 \mathrm{~cm}$ (inter-dunes and poplar land) and $40 \mathrm{~cm}$ (shrub land) with the values of $13.55,17.09,11.17$ and $2.80 \%$, respectively. However, soil moisture in cropland showed an increasing trend from 0 to $120 \mathrm{~cm}$. In summer (Fig. 5b), soil moisture in poplar land, grassland and interdunes showed a single peak with depth increasing, and the peak value appeared at 90,90 and $110 \mathrm{~cm}$, respectively. Meanwhile, in cropland and shrub land, soil water exhibited two peaks, and the peak values appeared at $60,110 \mathrm{~cm}$ and 20,110 cm, respectively. In autumn (Fig. 5c), soil moisture of all the land uses were observed similar stable trend with depth increasing, except that soil moisture of grassland showed a relatively smooth trend at $0-100 \mathrm{~cm}$ and gradually declined from $16.15 \%$ at $100 \mathrm{~cm}$ to $3.09 \%$ at $120 \mathrm{~cm}$. 

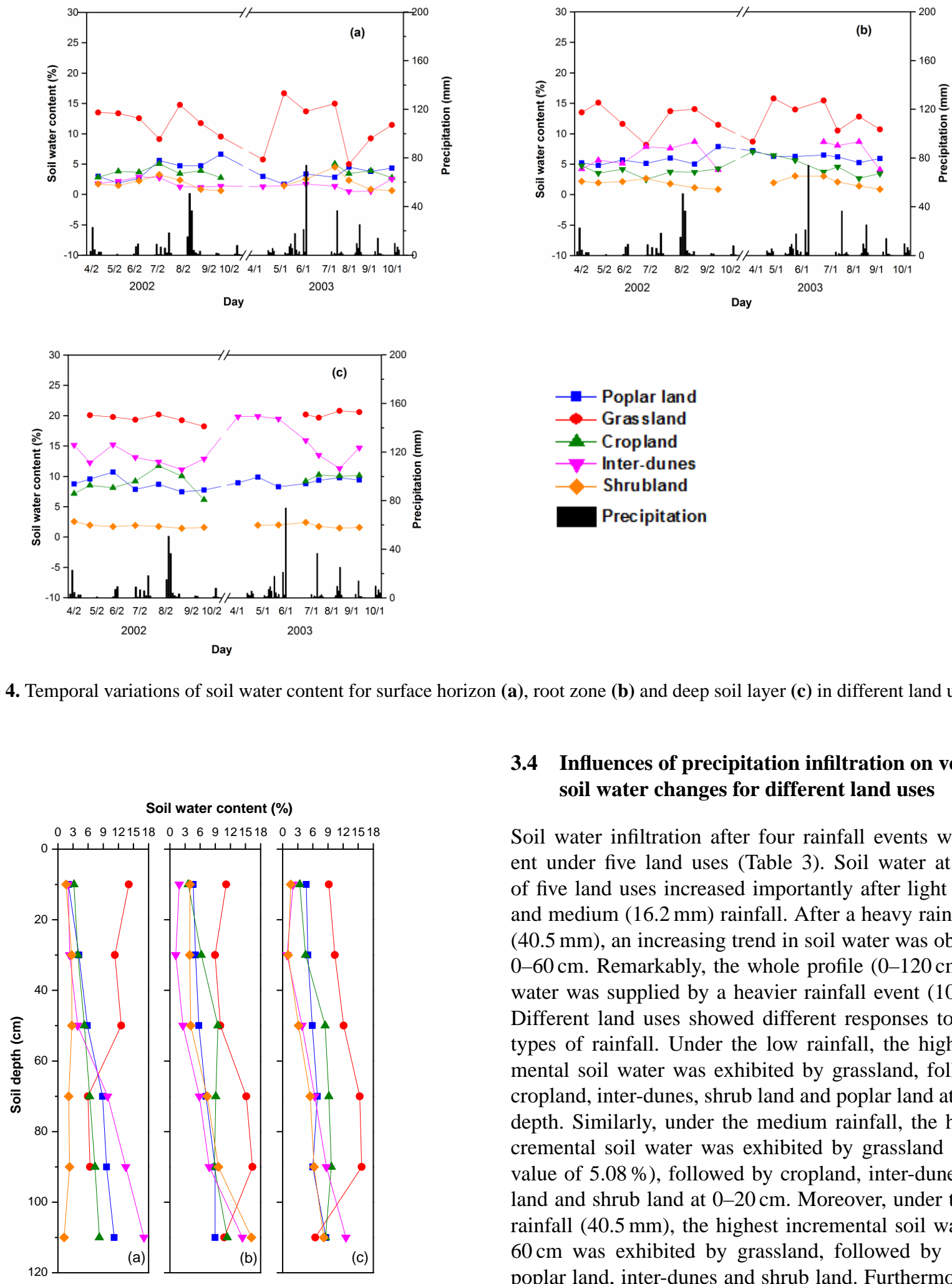

$\rightarrow$ Poplar land $\rightarrow$ Grassland $-\triangle$ Cropland $\rightarrow-$ Inter-dunes $\rightarrow$ Shrubland

Figure 5. Seasonal patterns of vertical soil water variations for different land uses: spring (a), summer (b) and autumn (c).

\subsection{Influences of precipitation infiltration on vertical soil water changes for different land uses}

Soil water infiltration after four rainfall events was different under five land uses (Table 3). Soil water at $0-20 \mathrm{~cm}$ of five land uses increased importantly after light $(2.6 \mathrm{~mm})$ and medium $(16.2 \mathrm{~mm})$ rainfall. After a heavy rainfall event $(40.5 \mathrm{~mm})$, an increasing trend in soil water was observed at $0-60 \mathrm{~cm}$. Remarkably, the whole profile $(0-120 \mathrm{~cm})$ of soil water was supplied by a heavier rainfall event $(102.4 \mathrm{~mm})$. Different land uses showed different responses to the four types of rainfall. Under the low rainfall, the higher incremental soil water was exhibited by grassland, followed by cropland, inter-dunes, shrub land and poplar land at $0-20 \mathrm{~cm}$ depth. Similarly, under the medium rainfall, the higher incremental soil water was exhibited by grassland (with the value of $5.08 \%$ ), followed by cropland, inter-dunes, poplar land and shrub land at $0-20 \mathrm{~cm}$. Moreover, under the heavy rainfall $(40.5 \mathrm{~mm})$, the highest incremental soil water at 0 $60 \mathrm{~cm}$ was exhibited by grassland, followed by cropland, poplar land, inter-dunes and shrub land. Furthermore, under the extreme heavy rainfall $(102.4 \mathrm{~mm})$, the highest incremental soil water at $0-120 \mathrm{~cm}$ was grassland (with the value of $18.25 \%$ ), followed by cropland, poplar land, inter-dunes and shrub land. 
Table 3. Soil water variations (\%) for different depth at $0-120 \mathrm{~cm}$ after four precipitation events. The values in the table represent the absolute difference between soil water content after rainfall and that before rainfall. Significant changes are bold, and negative values represent soil water content decreases.

\begin{tabular}{|c|c|c|c|c|c|c|c|c|c|c|}
\hline \multirow{2}{*}{$\begin{array}{l}\text { Precipitation event } \\
\text { Soil depth }(\mathrm{cm})\end{array}$} & \multicolumn{5}{|c|}{ Low $(2.6 \mathrm{~mm})$} & \multicolumn{5}{|c|}{ Medium (16.2 mm) } \\
\hline & Poplar & Grass & Crop & Inter-dunes & Shrub & Poplar & Grass & Crop & Inter-dunes & Shrub \\
\hline $0-20$ & 0.55 & 4.75 & 1.34 & 0.71 & 0.64 & 0.85 & 5.08 & 1.83 & 0.76 & 0.69 \\
\hline $20-40$ & -0.07 & -0.14 & -0.06 & -0.08 & -0.02 & -0.05 & -0.31 & -0.9 & -0.59 & -0.15 \\
\hline $40-60$ & 0.03 & -0.15 & -0.06 & -0.09 & -0.07 & -0.05 & -0.03 & -0.99 & -0.12 & -0.13 \\
\hline $60-80$ & -0.1 & -0.07 & -0.04 & -0.13 & 0.09 & -0.01 & 0.15 & -0.03 & -0.2 & -0.03 \\
\hline $80-100$ & -0.05 & -0.04 & -0.01 & -0.04 & -0.05 & -0.01 & -0.02 & -0.02 & -0.12 & -0.01 \\
\hline $100-120$ & -0.03 & 0.01 & -0.01 & -0.01 & -0.02 & -0.01 & -0.01 & 0.01 & 0 & 0 \\
\hline Incremental (\%) & 0.58 & 4.75 & 1.34 & 0.71 & 0.64 & 0.85 & 5.08 & 1.83 & 0.76 & 0.69 \\
\hline Precipitation event & \multicolumn{5}{|c|}{ High (40.5 mm) } & \multicolumn{5}{|c|}{ Extreme high (102.4 mm) } \\
\hline Soil depth (cm) & Poplar & Grass & Crop & Inter-dunes & Shrub & Poplar & Grass & Crop & Inter-dunes & Shrub \\
\hline $0-20$ & 1.85 & 5.13 & 2.58 & 1.92 & 1.25 & 2.98 & 4.83 & 3.95 & 2.33 & 2.18 \\
\hline $20-40$ & 0.68 & 3.77 & 1.9 & 1.63 & 1.02 & 2.82 & 3.72 & 2.41 & 2.21 & 2 \\
\hline $40-60$ & 0.56 & 1.45 & 0.96 & 0.41 & 0.35 & 2.52 & 3.2 & 2.37 & 2.15 & 1.35 \\
\hline $60-80$ & -0.29 & -0.97 & -0.65 & -0.68 & 0.04 & 2.33 & 2.46 & 2.17 & 2.36 & 1.29 \\
\hline $80-100$ & -0.06 & -0.04 & -0.08 & -0.06 & -0.02 & 1.57 & 2.11 & 1.88 & 2.03 & 1.06 \\
\hline $100-120$ & -0.01 & 0.01 & -0.01 & 0 & -0.01 & 1.05 & 1.93 & 1.44 & 1.65 & 1.78 \\
\hline Incremental (\%) & 3.09 & 10.35 & 5.44 & 3.96 & 2.58 & 13.27 & 18.25 & 14.22 & 12.73 & 9.66 \\
\hline
\end{tabular}

\section{Discussion}

\subsection{Soil moisture variability for different land uses}

\subsubsection{Temporal variations of mean soil moisture within $0-120 \mathrm{~cm}$}

The variations of mean soil moisture in different land uses were not always consistent with the rainfall (Fig. 3). This is because the "dry" sequence appeared (Fu et al., 2003). In arid land, the soil moisture content often reached its highest value after a heavier rain, and when the rain had stopped for a couple of days, the soil moisture content decreased sharply due to evapotranspiration, absorbed by roots or runoff etc. While several small rain events occurred, the soil moisture content did not increase and kept decreasing in some land uses. Then we called it "dry" sequence. Although several small rain events occurred in July 2002 and 2003, they did not interrupt the dry trend. Further, soil moisture content reaching peak value corresponded to the amount of precipitation, and that the higher mean moisture contents appear after heavier rain. However, there were differences in response to the rain due to land uses. For example, the peak in mean soil moisture content for cropland in 2002 and poplar land in 2003 showed a lag effect following a rain event (Fig. 3), because of the interception by canopy and the buffering influence of groundcover.

Moreover, the temporal variations of soil moisture profile changed with precipitation (Fig. 4). Surface $(0-20 \mathrm{~cm})$ soil water for all different land uses correlated positively with precipitation events (Fig. 4a); in root zone $(0-80 \mathrm{~cm})$, soil water showed a complicated trend due to evapotranspiration (Fig. 4b). There are two potential explanations. First, the effects of the root distribution on soil moisture may contribute to this difference (Sala et al., 1992). Second, vegetation possibly transforms the soil's physical properties, such as soil bulk density, physical composition and porosity (GarciaRuiz, 2010). These changes, in turn, influence the infiltration rate, storage, and redistribution of soil water (Lipiec et al., 2006). However, the deep soil layer $(80-120 \mathrm{~cm})$ had a relatively smooth temporal change, a clear lag in response to precipitation.

Under different land uses, however, the temporal variations of soil water in surface, root zone, and deep soil layer were observed following rainfall patterns, similar temporal evolutions of soil water at different profiles existed (Fig. 4). This implied that land use influenced on spatial patterns however insubstantial on temporal variations of soil water (Gao et al., 2014). Accordingly, precipitation was the main factor that affected soil water and caused similar trends of temporal patterns for different land uses. Therefore, land use was the main reason that affected the spatial variations, and precipitation was the main factor that influenced the temporal patterns, which was consistent with the recent findings from Yao et al. (2012). 


\subsubsection{Profile variations of soil moisture in different land uses}

There is a significant difference on the surface $(0-20 \mathrm{~cm})$ soil water among different land uses (Table 2). This is not consistent with the results that showed variations of $0-20 \mathrm{~cm}$ soil water in different land uses were low over the growing seasons in the hilly area of the Loess Plateau (Chen et al., 2007). Because most of the time soil moisture is controlled by factors such as soil texture, vegetation, aspect of the hillslope or local topography, and sometimes in semiarid land, it seems that there are other factors, such as topographical and vegetation presence, with a major influence on soil water content (Gómez-Plaza et al., 2000). Therefore, the differences of soil moisture variations between these two areas might due to the different soil texture, topography and vegetation cover. Moreover, soil surface moisture of grassland was significantly higher than the other land uses $(p<0.05)$, because of the higher clay content (Table 1) and the high water holding capacity of the surface soil. And soil surface moisture of inter-dunes was significantly lower than the other land uses, because of the poor permeability result from heavy clay soil, and the effective water content was low (Li et al., 2010). Also, there were statistical differences $(p<0.05)$ of soil water in both root zone and deep soil layer for different land uses (Table 2). This may be the result of different evapotranspiration patterns due to various distributions of plant root under different land uses (Gao et al., 2014).

Clearly, the profile of soil moisture indicated distinct vertical patterns for various seasons (Fig. 5). In spring, two types were classified as increasing and waving types; these are based on soil moisture changes with depth. Cropland showed the increasing type, likely due to the low evapotranspiration in spring (Qiu et al., 2011; Stéfanon et al., 2014; Yang et al., 2014) and the loose soil characteristic for rainfall infiltrating. The waving type consisted of poplar land and shrub land, grassland and inter-dunes, where soil moisture presented a low-high-low change in profile. A possible explanation was the different soil bulk density and root distribution.

Moreover, in summer, soil moisture in the poplar land, grassland, and inter-dunes presented a low-high-low change with depth, while the cropland and shrub land presented a low-high-low-high-low change, likely due to the different evapotranspiration of different vegetation ( $\mathrm{Li}$ et al., 2009; Wagendorp et al., 2006).

Furthermore, soil moisture showed a stable (high-lowhigh-low) trend with wave-changing type at $0-120 \mathrm{~cm}$ except grassland in autumn (Fig. 5c). Grassland soil moisture gradually decreased with depth from 100 to $120 \mathrm{~cm}$, which was not consistent with the recent findings (Gao et al., 2014). The possible reason was the differences in topography, which was the main factor controlling time stability (Gómez-Plaza et al., 2000).

\subsection{Differences in soil moisture and infiltration among land cover types}

In general, the infiltration process is controlled by precipitation patterns, ground cover, soil characteristics, slop and initial soil moisture (Gabarrón-Galeote et al., 2013; GómezPlaza et al., 2000; Wang et al., 2013), which in turn affects soil water.

In our study, the amount of medium precipitation was 6.2 times that of low rainfall; however the increase of soil water after medium precipitation was only 1.2 times that after low precipitation. The reason is that vegetation just begin to come into leaf in the early growing season (low precipitation), and that plants can intercept part of precipitation with thick branches and luxuriant foliage in mid-June (medium precipitation) (Gao et al., 2014). This is consistent with the result reported by Wang et al. (2005) that shrub community (C. korshinskii kom) canopy interception was $11.7 \%$ of the precipitation. Furthermore, the study suggested that infiltration depth increased with the increase of precipitation, indicating that infiltration depth will be greater than $120 \mathrm{~cm}$ after heavier precipitation (Table 3). Similarly, Yao et al. (2013) reported that infiltration depth increased with increasing precipitation amount. Although a positive correlation was indicated between precipitation and infiltration depth, it is difficult to quantify the relationship due to the varying initial soil water content, rainfall intensity, vegetation cover, and meteorological conditions among the four precipitation events (Gao et al., 2014).

Moreover, vegetation affecting on precipitation interruption for soil was to influence soil water by changing precipitation and soil properties (Li et al., 2013). In our study, there were no obvious differences on infiltration depth after four types of precipitation intensity, but the incremental soil water was different in different land uses. Under the low rainfall condition, incremental soil water of poplar land was less than that of the other land uses. The possible reason was that the vegetation canopy and litter stopped precipitation from entering the soil. Furthermore, under other three types of precipitation, incremental soil water in shrub land (C. korshinskii kom) was smaller than that of the other land uses. The first reason was that soil water runoff was strong on shrub land due to the effect of slope (Adekalu et al., 2007) and the second reason was that shrub community was set up on mobile dunes where the soil evaporation was intense and vegetation cover was low. On the contrary, higher vegetation cover of other land uses prevented from direct solar radiation to surface soil and high clay (Table 1) led to higher water-holding capability.

Furthermore, land type of inter-dunes had a higher soil bulk density and clay content (Table 1), leading to a slow infiltration rate, and the incremental soil water was smaller than cropland, poplar land and grassland (Fig. 3). Therefore, it could maintain a high soil water level for a long time, which contributed to the growing herbaceous plants. As discussed 
above, both grassland and inter-dunes could maintain higher soil moisture, which would be beneficial for the stable development of plant community in this landscape.

\subsection{Implications for soil and water conservation}

Climate change affects the hydrological cycle (Parry et al., 2007) and is likely to reduce summer precipitation over the central parts of arid and semi-arid Asia. This will aggravate water conditions, leading to serious desertification. Therefore, it is vitally important to make efficient use of the limited water resources to improve the ecological environment and agricultural water management in these regions (Gao et al., 2014).

Because cropland could induce severer soil erosion and land degradation, other land uses in terms of artificial forest and shrub (e.g., poplar and C. korshinskii kom in our site) and natural rehabilitation (e.g., fenced grassland in our site) have been suggested to plant and protect by fence (Zhang et al., 2012). In addition, soil moisture of deep layer in shrub land was significantly lower than that in the other land uses (Table 2), soil moisture would decline in C. korshinskii kom shrub land for the reason soil water could not get the supplement from the deep soil water resulting from $C$. korshinskii kom had deep and enormous roots for water uptake (She et al., 2013). Moreover, surface soil water of poplar land was significantly $(P<0.001)$ lower than that in grassland (Table 2), and water consumption of poplar was higher than grassland vegetation (Kang et al., 2008), therefore, the surface soil layer could be dry and deteriorate due to precipitation interruption and deep-root water uptake (Wang et al., 2013). Consequently, this would result in the competitive disadvantage of deep-rooted trees and shrub. If this situation continued, "low, thin, old trees" and further degradation might occur (Zhao et al., 2009). In the light of high soil moisture maintained in grassland and inter-dunes, herbaceous plants are likely to be an adaptive and stable vegetation type under this environmental condition.

Furthermore, catchment water balance and the factors that affected water balance were influenced by different land uses. Dai et al. (2006) reported that land use was the main factor that affected water balance and evapotranspiration was the largest expenditure in land water balance. Moreover, comparison (from high to low) of the evapotranspiration in different land uses was cropland, arbor, shrub land and grassland (Kang et al., 2008). In addition, our study indicated that surface soil moisture exhibited relatively low values $(<5 \%)$ during the growing season (May-July) (Fig. 4a). Thus, an irrigation scheme must be worked out to meet the water requirement and then increase soil water utilization according to soil water content and evapotranspiration.

Overall, during the process of vegetation recovery in an arid region, we should analyze in more detail the spatial and temporal variations of soil water for different land uses and the factors that affect the soil water of different vegetation.
We should also reasonably manage efficient water use to maintain the water balance and the development of a stable vegetation community.

\section{Conclusions}

Different land uses contributed to the soil moisture variations along with rainfall, topography and soil properties. The temporal variations of mean soil moisture in different land uses were not always consistent with the rainfall due to the dry sequence. The cropland and poplar land showed a lag effect following a rain event due to the canopy interception and the buffering influence of groundcover. Moreover, soil water in surface, root zone and deep soil layer indicated statistical differences under different types of land cover. Meanwhile, Soil water profiles under different land uses that changed with precipitation, soil water in surface, and root zone horizons were driest during April to September, and soil water lag was observed in deep soil layer. Vertical soil water profiles exhibited seasonal patterns for different land uses, and the stable layer of soil moisture was found at $80-120 \mathrm{~cm}$. Moreover, a positive correlation existed between precipitation and infiltration depth for all land uses. Those results give us an insight into land and water management, an irrigation scheme must be worked out to meet water requirements based on soil water content and evapotranspiration, thereby improving water use efficiency. All of this could also help to control soil erosion and land degradation better. Grassland represented more adaptive vegetation in this area. Therefore, the local government should establish fenced meadow and decrease grazing properly to protect natural grassland and plant trees with the reasonable density in the flowing sandy land and inter-dune land.

Acknowledgements. We thank Yongming Luo and Hongmei Wang for assistance with field and laboratory work. The project was supported by the State Key Laboratory of Forest and Soil Ecology (LFSE2014-06) and the National Basic Research Program of China (2013CB429902). The authors gratefully acknowledge the financial support and Ulan'aodu Station for providing climate data of this region.

Edited by: P. Pereira

\section{References}

Abadi Ghadim, A. K.: Water repellency: a whole-farm bioeconomic perspective, J. Hydrol., 231-232, 396-405, 2000.

Adekalu, K. O., Olorunfemi, I. A., and Osunbitan, J. A.: Grass mulching effect on infiltration, surface runoff and soil loss of three agricultural soils in Nigeria, Bioresource Technol., 98, 912-917, 2007.

Alamusa, Niu, C. Y. and Zong, Q.: Temporal and spatial changes of freeze-thaw cycles in Ulan'aodu region of Horqin Sandy Land, 
northern China in a changing climate, Soil Sci. Soc. Am. J., 78, 89-96, 2014.

Benegas, L., Ilstedt, U., Roupsard, O., Jones, J., and Malmer, A.: Effects of trees on infiltrability and preferential flow in two contrasting agroecosystems in Central America, Agr. Ecosyst. Environ., 183, 185-196, 2014.

Biro, K., Pradhan, B., Buchroithner, M., and Makeschin, F.: Land use/land cover change analysis and its impact on soil properties in the northern part of gadarif region, Sudan, Land Degrad. Dev., 24, 90-102, 2013.

Brevik, E. C., Cerdà, A., Mataix-Solera, J., Pereg, L., Quinton, J. N., Six, J., and Van Oost, K.: The interdisciplinary nature of SOIL, SOIL, 1, 117-129, doi:10.5194/soil-1-117-2015, 2015.

Cerdà, A.: Soil aggregate stability under different Mediterranean vegetation types, Catena, 32, 73-86, 1998.

Cerdà, A.: Seasonal and spatial variations in infiltration rates in badland surfaces under Mediterranean climatic conditions, Water Resour. Res., 35, 319-328, 1999.

Cerdà, A.: Aggregate stability against water forces under different climates on agriculture land and scrubland in southern Bolivia, Soil Till. Res., 57, 159-166, 2000.

Chen, L. D., Huang, Z. L., Gong, J., Fu, B. J., and Huang, Y. L.: The effect of land cover/vegetation on soil water dynamic in the hilly area of the loess plateau, China, Catena, 70, 200-208, 2007.

Dai, J., Chen, J., Cui, Y., He, Y., and Ma, J.: Impact of forest and grass ecosystems on the water budget of the catchments, Adv. Water Sci., 17, 435-443, 2006 (in Chinese with English Abstract).

Doerr, S. H., Shakesby, R. A., and Walsh, R. P. D.: Soil water repellency: its causes, characteristics and hydro-geomorphological significance, Earth-Sci. Rev., 51, 33-65, 2000.

Finley, C. D. and Glenn, N. F.: Fire and vegetation type effects on soil hydrophobicity and infiltration in the sagebrush-steppe: II. Hyperspectral analysis, J. Arid Environ., 74, 660-666, 2010.

Fu, B. J., Wang, J., Chen, L. D., and Qiu, Y.: The effects of land use on soil moisture variation in the Danangou catchment of the Loess Plateau, China, Catena, 54, 197-213, 2003.

Fu, T. G., Chen, H. S., Zhang, W., Nie, Y. P., and Wang, K. L.: Vertical distribution of soil saturated hydraulic conductivity and its influencing factors in a small karst catchment in Southwest China, Environ. Monit. Assess., 187, 4320, doi:10.1007/s10661015-4320-1, 2015.

Gabarrón-Galeote, M. A., Martínez-Murillo, J. F., Quesada, M. A., and Ruiz-Sinoga, J. D.: Seasonal changes in the soil hydrological and erosive response depending on aspect, vegetation type and soil water repellency in different Mediterranean microenvironments, Solid Earth, 4, 497-509, doi:10.5194/se-4-497-2013, 2013

Ganjegunte, G. K., Sheng, Z., and Clark, J. A.: Soil salinity and sodicity appraisal by electromagnetic induction in soilsirrigated to grow cotton, Land Degrad. Dev., 25, 228-235, 2014.

Gao, X., Wu, P., Zhao, X., Wang, J., and Shi, Y.: Effects of land use on soil moisture variations in a semi-arid catchment: Implications for land and agricultural water management, Land Degrad. Dev., 25, 163-172, 2014.

Garcia-Ruiz, J. M.: The effects of land uses on soil erosion in Spain: A review, Catena, 81, 1-11, 2010.

Gomez-Plaza, A., Alvarez-Rogel, J., Albaladejo, J., and Castillo, V. M.: Spatial patterns and temporal stability of soil moisture across a range of scales in a semi-arid environment, Hydrol. Process., 14, 1261-1277, 2000.

Guo, L., Chen, J., and Lin, H.: Subsurface lateral preferential flow network revealed by time-lapse ground-penetrating radar in a hillslope, Water Resour. Res., 50, 9127-9147, 2014.

Helmke, M. F. and Losco, R. L.: Soil's influence on water quality and human health, in: Soils and human health, edited by: Brevik, E. C. and Burgess, L. C., Boca Raton, FL, USA, CRC Press, 155-176, 2013.

Huang, G., Zhao, X. Y., Li, Y. Q., and Cui, J. Y.: Restoration of shrub communities elevates organic carbon in arid soils of northwestern China, Soil Biol. Biochem., 47, 123-132, 2012.

Kang, L., Wei, Y., Li, L., Dong, F., and Wang, Y.: Analysis on Effect of Forest and Grass Vegetation Construction on Runoff in Sandy and Coarse Region, Water Power, 34, 31-34, 2008 (in Chinese with English Abstract).

Keesstra, S. D., Geissen, V., van Schaik, L., Mosse., K., and Piiranen, S.: Soil as a filter for groundwater quality, Curr. Opin. Env. Sust., 4, 507-516, 2012.

Leh, M., Bajwa, S., and Chaubey, I.: Impact of land use change on erosion risk: an integrated remote sensing, geographic information system and modeling methodology, Land Degrad. Dev., 24, 409-421, 2013.

Li, X. R., Tian, F., Jia, R. L., Zhang, Z. S., and Liu, L. C.: Do biological soil crusts determine vegetation changes in sandy deserts? Implications for managing artificial vegetation, Hydrol. Process., 24, 3621-3630, 2010.

Li, Y. Q., Sun, Y. J., Zhang, T. H., Luo, W. Q., Deng, Y., and Liu, X. P.: Responses of soil moisture under shrub Caragana microphylla to rainfall, Chinese J. Ecol., 32, 1097-1103, 2013 (in Chinese with English Abstract).

Li, Z., Liu, W. Z., Zhang, X. C., and Zheng, F. L.: Impacts of land use change and climate variability on hydrology in an agricultural catchment on the Loess Plateau of China, J. Hydrol., 377 , 35-42, 2009.

Lipiec, J., Kuś, J., Słowińska-Jurkiewicz, A., and Nosalewicz, A.: Soil porosity and water infiltration as influenced by tillage methods, Soil Till. Res., 89, 210-220, 2006.

Liu, R., Zhao, H., Zhao, X., Zuo, X., and Drake, S.: Soil macrofaunal response to sand dune conversion from mobile dunes to fixed dunes in Horqin sandy land, northern China, Eur. J. Soil Biol., 45, 417-422, 2009.

Markus, F., Hannes, F. William, A. J., and Leuenberger, J.: Susceptibility of soils to preferential flow of water: A field study, Water Resour. Res., 30, 1945-1954, 1994.

Molina, A., Govers, G., Vanacker, V., Poesen, J., Zeelmaekers, E., and Cisneros, F.: Runoff generation in a degraded Andean ecosystem: Interaction of vegetation cover and land use, Catena, 71, 357-370, 2007.

Mukhopadhyay, S. and Maiti, S. K.: Soil $\mathrm{CO}_{2}$ flux in grassland, afforested land and reclaimed coal mine overburned dumps: A case study, Land Degrad. Dev., 25, 216-227, 2014.

Neris, J., Jimenez, C., Fuentes, J., Morillas, G., and Tejedor, M.: Vegetation and land-use effects on soil properties and water infiltration of Andisols in Tenerife (Canary Islands, Spain), Catena, 98, 55-62, 2012.

Parras-Alcántara, L. and Lozano-García, B.: Conventional tillage versus organic farming in relation to soil organic carbon stock in 
olive groves in Mediterranean rangelands (southern Spain), Solid Earth, 5, 299-311, doi:10.5194/se-5-299-2014, 2014.

Parry, M. L., Canziani, O. F., Palutikof, J. P., Van der Linden, P. J., and Hanson, C. E.: Contribution of working group II to the fourth assessment report of the intergovernmental panel on climate change, Cambridge University Press, Cambridge, UK, 722, 2007.

Qiu, G. Y., Xie, F., Feng, Y. C., and Tian, F.: Experimental studies on the effects of the "Conversion of Cropland to Grassland Program" on the water budget and evapotranspiration in a semi-arid steppe in Inner Mongolia, China, J. Hydrol., 411, 120-129, 2011.

Sala, O. E., Lauenroth, W. K., and Parton, W. J.: Long-term soilwater dynamics in the shortgrass steppe, Ecology, 73, 11751181, 1992.

Sandvig, R. M. and Phillips, F. M.: Ecohydrological controls on soil moisture fluxes in arid to semiarid vadose zones, Water Resour. Res., 42, W08422, doi:10.1029/2005WR004644, 2006.

She, D., Xia, Y., Shao, M., Peng, S., and Yu, S.: Transpiration and canopy conductance of Caragana korshinskii trees in response to soil moisture in sand land of China, Agroforest. Syst., 87, 667678,2013

Starr, G. C.: Assessing temporal stability and spatial variability of soil water patterns with implications for precision water management, Agr. Water Manage., 72, 223-243, 2005.

Stéfanon, M., Schindler, S., Drobinski, P., de Noblet-Ducoudré, N., and D'Andrea, F.: Simulating the effect of anthropogenic vegetation land cover on heatwave temperatures over central France, Clim. Res., 60, 133-146, 2014.

Su, Y. Z., Zhao, H. L., Zhang, T. H., and Zhao, X. Y.: Soil properties following cultivation and non-grazing of a semi-arid sandy grassland in northern China, Soil Till. Res., 75, 27-36, 2004.

Taumer, K., Stoffregen, H., and Wessolek, G.: Seasonal dynamics of preferential flow in a water repellent soil, Vadose Zone J., 5, 405-411, 2006.

Thompson, S. E., Harman, C. J., Heine, P., and Katul, G. G.: Vegetation-infiltration relationships across climatic and soil type gradients, J Geophys. Res., 115, G02023, doi:10.1029/2009JG001134, 2010.

Wagendorp, T., Gulinck, H., Coppin, P., and Muys, B.: Land use impact evaluation in life cycle assessment based on ecosystem thermodynamics, Energy, 31, 112-125, 2006.

Wang, S., Fu, B. J., Gao, G. Y., Liu, Y., and Zhou, J.: Responses of soil moisture in different land cover types to rainfall events in a re-vegetation catchment area of the Loess Plateau, China, Catena, 101, 122-128, 2013.

Wang, X. P., Cui, Y., Pan, Y. X., Li, X. R., Yu, Z., and Young, M. H.: Effects of rainfall characteristics on infiltration and redistribution patterns in revegetation-stabilized desert ecosystems, J. Hydrol., $358,134-143,2008$.
Wang, X. P., Li, X. R., Zhang, J. G., Zhang, Z. S., and Berndtsson, R.: Measurement of rainfall interception by xerophytic shrubs in re-vegetated sand dunes, Hydrolog. Sci. J., 50, 897-910, 2005.

Yang, F. L., Zhang, Q., Wang, R. Y., and Zhou, J.: Evapotranspiration measurement and crop coefficient estimation over a spring wheat farmland ecosystem in the Loess Plateau, Plos One, 9, e100031, doi:10.1371/journal.pone.0100031, 2014.

Yao, S., Zhang, T., Liu, X., and Ma, Y.: Feature of soil saturated hydraulic conductivity in various lands of Horqin Sandy Land, J. Arid Land Resour. Environ., 26, 123-126, 2012 (in Chinese with English Abstract).

Yao, S., Zhao, C., Zhang, T., and Liu, X.: Response of the soil water content of mobile dunes to precipitation patterns in Inner Mongolia, northern China, J. Arid Environ., 97, 92-98, 2013.

Yu, Y., Wei, W., Chen, L. D., Jia, F. Y., Yang, L., Zhang, H. D., and Feng, T. J.: Responses of vertical soil moisture to rainfall pulses and land uses in a typical loess hilly area, China, Solid Earth, 6, 595-608, doi:10.5194/se-6-595-2015, 2015.

Zhang, H., Tong, W., Wang, N., Wang, H., Zhou, J., and Li, B.: Analysis on landscape pattern of land-use in Horqin Sandy Land on the background of conversion of cultivated land to grassland, J. Arid Land Resour. Environ., 26, 96-101, 2012 (in Chinese with English Abstract).

Zhang, X., Yu, G. Q., Li, Z. B., and Li, P.: Experimental Study on Slope Runoff, Erosion and Sediment under Different Vegetation Types, Water Resour. Manag., 28, 2415-2433, 2014.

Zhang, Y., Carey, S. K., Quinton, W. L., Janowicz, J. R., Pomeroy, J. W., and Flerchinger, G. N.: Comparison of algorithms and parameterisations for infiltration into organic-covered permafrost soils, Hydrol. Earth Syst. Sci., 14, 729-750, doi:10.5194/hess14-729-2010, 2010.

Zhao, X., Wu, P., Feng, H., Wang, Y., and Shao, H.: Towards Development of Eco-Agriculture of Rainwater-Harvesting for Supplemental Irrigation in the Semi-Arid Loess Plateau of China, J. Agron. Crop Sci., 195, 399-407, 2009.

Zheng, H., Gao, J. X., Teng, Y. G., Feng, C. Y., and Tian, M. R.: Temporal variations in soil moisture for three typical vegetation types in Inner Mongolia, northern China, Plos One, 10, e0118964, doi:10.1371/journal.pone.0118964, 2015.

Ziadat, F. M. and Taimeh, A. Y.: Effect of rainfall intensity, slope, land use and antecedent soil moisture on soil erosion in an Arid Environment, Land Degrad. Dev., 24, 582-590, 2013.

Zuo, X., Zhao, H., Zhao, X., Guo, Y., Yun, J., Wang, S., and Miyasaka, T.: Vegetation pattern variation, soil degradation and their relationship along a grassland desertification gradient in Horqin Sandy Land, northern China, Environ. Geol., 58, 1227 1237, 2009. 